\title{
Social Function of Poetry From View of New Criticism
}

\author{
Mohammad Khosravishakib \\ Department of Persian Language and Literature, Human Science Faculty, Lorestan University, I. R. Iran \\ E-mail: M.khosravishakib@gmail.com
}

Received: 06-09-2016

Accepted: 11-11-2016

Advance Access Published: January 2017

Published: 01-03-2017

doi:10.7575/aiac.ijalel.v.6n.2p.14

URL: http://dx.doi.org/10.7575/aiac.ijalel.v.6n.2p.14

\begin{abstract}
The standards, morality and function of poetry lie in its correctness and truthfulness to the state of mind it is trade with, not in its themes. The matter of decency and correctness in poetry and poems is a controversial one. Commonly seen as a fictional category which have a tendency to toward subjectiveness and perception, it is frequently tough to conclude whether the moral sense of poetry is to be found in its content, its method, in the feelings transported, or in the linking of these features. Here this subject is scrutinized as it appears in the supposed of faultfinders linked to the so titled New Criticism school. Prominent during the mid-20th Century, this school was recognized for its emphasizing on the reading of interior and formal possessions of the literary manuscript. On the other hand, the authors related to it had sumptuous philosophies on morality in poetry and poem. Here some of these concepts are conversed.
\end{abstract}

Keywords: Winter, Eliot, Tate, Poetry, New Criticism, Morality

\section{Introduction}

These inquiries will be surveyed in this paper, in kith and kin to one exact art, I mean poetry and poem. Poetry is frequently perceived as a more mental and ambiguous type in literature. Its subjects are often individual or abstract, its compositional developments are puzzling, mostly in contemporary poetry and the concepts it delivers are seen as secretive. Many knowledgeable literature readers mention that they do not know how to assess the value and worth of a verse or even that there is simply no way to estimate it, that poetry is not meant to be assumed or assessed, only imprecisely "sensed." It is understandable that so ambiguous an art would scarcely endure during the centuries in accurately all human cultures. Poetry has confidently, equally additional arts, played a part in human culture, even if this part is not every time strong. Insisted by these problems, poets and criticizers such as T. S. Eliot, I. A. Richards and Ezra Pound and Nima Yooshig in Persian contemporary poetry fixed to provide more compact and objective examines of the poetic occurrence, procreating a group of criticizers questionably and somehow capriciously named "the new critics." The works of this group were perhaps the best poetry criticism written in the 20th Century. While these writers became known for their highlighting on the study of poetic works' interior structure, a great deal of echo on the moral and communal duty and contribution of poets was provided by them. This article aims to provide a short-lived and general view of their reflections on these topics. The topic of decency and morality in art and literature has permanently been very tough in the ground of aesthetics. All the same, it remnants an unclear and ambivalent topic. There is slight hesitation about the decent and moral worth and accountability of the researcher. On the other hand, the artist's, is murky and debatable. Where does ethics and morality give the impression in art? In its subjects? In its procedure and structure? In the artist's opinion on his or her matters?

\section{Discussion}

\subsection{Communal Concern of Poetry}

Requesting of the poet's concern is forthrightly put in a 1952 paper by Allen Tate (1998) previously in the heading: To whom is the poet responsible? Asks the poet and faultfinder. He put answer to this fundamental question by himself as below conception:

"The total complex of sensibility and thought, of belief and experience, in the society from which the poetry emerges, is the prime limiting factor that the poet must first of all be aware of; otherwise, his language will lack primary reality, the connection of thing and word. (Tate, 1999. p. 27)

The response he stretches, though not so straightforward as the question, is nevertheless self-assured and strong: the poet is in charge with his own morality, for his personal poetry. Tate exposes us that the poet as other writers was held responsible for much of the confusion that quivered the 20th Century in the form of conflicts and hostilities and tyrannical governments. It was said that this road taken by poetry in contemporaneousness, had led to unfriendly spiritual behaviors, to a flouting of awareness leading to those instabilities. Tate, on the other hand, repeating us that "the human condition must be faced and embodied in language before men in any age can envisage the possibility of 
action" (Tate, 1999. p. 27), so, the poet's concern is with human practice and its translation into language, with his skills and mechanism. Tate is also insisting on effective involvement and contribution of poets in the party-political life of their republic or the use of their respect as poets to hold political locations. In this intelligence he mentions Pound, who became recognized for his political accomplishments. Pound had a systematic opinion on the artist's specifically the poet's obligation to his society and it was in trace with his specific outlooks on what poetry was. Pound explains literature as "language charged with meaning to the utmost possible degree" (Pound: 2008, p. 23). This stimulating of language suggests exploring its sensitive opportunities and funds as much as probable. Such explanation of literature is openly associated to a purpose of literature in its society, for the State and its politic preservation. When one considers about it, it becomes faultless that the health of a state is severely depending on the interpretations, ideas, and organizations of thought grounding it; and the working of these depends on language, on the rulers' dimensions of communication among themselves and with their people, and, lastly, with other nation-states. In other words, the comprehensive management of a country depends on reliability of thought, and reliability of though depends on reliability and lucidity of language, insofar as thought must be communicated. And, lastly, the one who is really in charge with the reliability and lucidity of language is, after all, the writer and poet. Pound and Nima Yooshij talk about literature in general, but poetry here has a superior weightiness. For Nima Yooshij, the reliability of a society is extremely hooked on the quality of its literature especially on poetry. As an challenge to contribute to the conservation of reliability and soundness in language through poetry, Nima Yooshij proposes a technique for reading poetry which would be equivalent to that of natural sciences: one desires to look cautiously at the texts and see what is actually there in terms of language possessions, how the poet uses language and how and to what degree this supply he or she travels can be gainful for the general language consumer. With these perceptions and ideas Pound and Nima Yooshij attempt to provoke poetry criticizers and person who reads or poets with more objective and well reading routines. In extra essay, The Serious Artist (1968), Pound extends his considerate of the artist's concern. Art, for Pound, is a skill as same as chemistry; its issue is mankind, manhood and the person, what makes mankind what it is and in what personalities differ from each other. This is the concern of the artiste. Art, according to Pound, is corrupt in as much as it is bad, i.e., improper art. He believes that inaccurate art is as immoral as a mixed healing report, and the immoral artist ought to be penalized and scorned, just as the illegal surgeon. The standards and morality of art lies in its correctness and truthfulness to the state of mind it is trade with, not in its themes. With concern to this fact, Pound utters that "good art however 'immoral' it is, is wholly a thing of virtue" (Pound; 2008. p. 44). Nima Yooshij and Tate's and Pound's philosophies on the utility and concern of poetry are engrossed above all on the superiority of language and its special effects on a society as an all-inclusive. T. S. Eliot, in The Social Function of Poetry (1975) goes in the same direction, but discovers these ideas with more delicacy, particularly in what worries the relation of the poet with his or her society. Head of all, Eliot indications that in different epochs of time poetry has had different certain occupations. It's accurate to say that it has continually had a religious function and purpose, as in religious hymns or even prayers, but in old-style cultures it has also an incantatory -dreamlike occupation; during the classical ancient times, in adding to its role as amusement, it had also a moralistic function, which is now evidently vanished. On the other hand, utters Eliot, there is certain role which is held by poetry in all eras and all cultures, and which actually illustrates it as poetry. The first role is giving pleasure, but above and beyond pleasure, poetry need transport some new kind of experience or at least to afford the reader with innovative words to direct and denote his or her prior experiences, expansion his or her vocabulary and field of awareness. These roles, however, concern the individual, not the collectivity. For the communal length, Eliot agrees with Pound and Nima Yooshij that poetry is designed to conserve a people's language healthy and operative, chiefly in what concerns the sensitive length of a language. Eliot prompts us that to feel in a language, more than to speak it or think in it, is the deepest degree of closeness one can have with it. It is this ability of thinking in one's mother language that forms one's personality, to which Eliot enlarges that getting another language, is getting a complementary personality. Thought can frequently be translated from one language into another with no damage of content, but the emotional tone occurs only in that specific language. The opportunity a language has to express and convey delicate and more polished shades of emotion reflects straight in its people's refinement or crudeness of emotions. Once a language starts rotting, losing its capacity of handover feeling, the emotions of its speakers become increasingly crude, with a consequential corruption in this people's intellect and culture up to the point of the whole demolition of its development and extinction of its language.

This polished and complete emotional length in language is the playing field in which poetry acts. The apprehension of the poet, subsequently, is his language only indirectly, to his people. Moreover, Eliot repeats us that, within his language the poet must have a wide-ranging consciousness in relations of time and space. He must be aware of the advancement of his language's possessions as well as of its actualization in different social levels. The earlier is important because, in order to use his language the best he can in his own time, he must learn how it was used by those who used it finest in former times; the latter is important because, even if the poet will discover more polished and delicate emotions in his work, he must have something to say to all his colleague people, even those of lower degrees of learning and culture, is he to mirror his nation's personality in his work.

\subsection{The Poetry's Moralities Grounded on New Criticism}

The connection between morality and literature is certainly repeatedly affected upon by the new critics, at least in those studied by Ransom. Significantly New Criticism took its name from a book by John Crowe Ransom at first published in 1941 where he scrutinizes the work of three prominent "new critics" as he calls them: Yvor Winters, I. A. Richards and T. S. Eliot. Ransom announces that this new criticism, "in depth and precision at once it is beyond all earlier criticism in our language" (Ransom; 1979, p. 50). Ransom also arguments two difficulties of this new leaning, one related to the use 
of psychological terminology and the other well-defined as "plain moralism, which in the new criticism would indicate that it has not unbound itself from the old criticism" (Ransom; 1979, p. 5), pointing Eliot as mostly affected by it. Eventually, Ransom held a "criticism of the structural properties of poetry" (Ransom; 1979, p. 12), since these possessions were what describe poetry as something different from other occurrences. Interestingly enough, these writers, in spite of their resemblances concerning critical restraint, present quite diverse ontological foundations, which touch their views on moralities. Regarding ontology, we have a manifest antagonism between Richards's materialistic psychological opinion and Eliot's which in different ways are set up on religious ideas.

Ransom put analysis in Richards his "long and faithful piety to neurological psychology" (Ransom; p. 13) and his trusting respect of the tough sciences and their methods. Certainly, learning his chief work, Principles of Literary Criticism (2001), firstly published in 1924, one is fascinated by the majority of psychological and neurological ideas in his opinions on aesthetics. First on, Richards's states that the variance between aesthetic experience and other kinds of experience is in the "connections of their constituents" (Richard; p. 12) Art is, for Richards, first of all worried with announcement. He does not disregard individual or unconscious rudiments in the writing of a poem or the production of any art object, but he clearly says that these elements are profound, and the features which give a work of art its legitimacy are particularly those based on which a common experience can be shared; in other words, those basics which may permit a communication of experiences. Arts are "our storehouse of recorded values" (Richard; p. 27). Human moral growth is based on the contrast of practices and their values in order to select experiences to be preferred, and without the help of the arts, very limited experiences could be compared, and clearly the greatest obscure and complex would be left out, due to the difficulty of communicating them. The able artist is the one who do fine in shared those experiences, expanding our range of known experiences and, then, of values.

In the arts we find the records in the only form in which these things can be recorded of the experiences which have seemed worth having to the most sensitive and discriminating persons. (Richard; p.27-28)

In this structure of arts and morals, Richard have faith in, "is as much concerned with the health of the mind as any doctor with the health of the body" (Richard; p. 54), a simile close to that of Pound: "it is important for the purpose of thought to keep language efficient as it is in surgery to keep tetanus bacilli out of one's bandages" (Pound; 2008, p. 23). The concept that poetry is associated to the well-being of a culture is very common in these critics.

Ransom notes that Eliot's religious opinions are not fixed in his criticism, that he continued a good degree of nonalignment when writing criticism. Some of Eliot's policy on the task of literature was outlined above and, no religious opinions were used. But, one should mention that in the paper declared above, The Social Function of Poetry, Eliot forms that his objective is to trace the role poetry has had throughout the centuries in all human cultures. When talking about the role of literature in Europe or the wide-ranging Western world, the place of religion is strongly determined. In his frequently recited essay Tradition and the Individual Talent (1975), Eliot utters that what gives an artist his real personality is not his differences with his predecessors, but actually his similarities. Individual ability is not at odds with tradition; in fact, it is a direct result from or part of it. True personality growths from convention. Eliot in Religion and literature (1975) evaluates the open-minded view that "if everybody speaks what he thinks, and does what he likes, things will somehow, by some automatic benefit and change, will come right in the end" (p. 103). Certainly, Eliot's view of personality was opposite to that of autonomous freethinking. His celebrated quotation like this:

"Poetry is not a turning loose of emotion, but an escape from emotion; it is not the expression of personality, but an escape from personality,"

Is more misleading. This judgment in Tradition and the Individual Talent can be sometimes misrepresentative and misleading. For Eliot, artistic expansion requires a depersonalization, an extinction of personality, and a fascination of the artist into his or her convention and tradition. Poetic structure is effective, chiefly, done by engagement of what Eliot called "objective correlative," a series of items and pictures, which, in the poem, would substitute, or symbolize, a certain quality of emotion. Eliot does not say that a poet should not trust on his own emotions and subjective experiences in the writing of his poems, but he goads us that the poet has to transaction with these emotions and experiences as factually as possible. There should be no difference for a poet between writing from his own capabilities and experience or those of others, since these materials would go through the filter of convention, more than the poet's personality, and they would be dealt with by a set of impersonal structures. The poem, at that point, becomes a completely different thing from the experiences and emotions that first stimulated it. From all the critics studied by Ransom Eliot and Winter is the one most nonstop interested in the relatives between morality and poetry. His interest in morality is scolded by Ransom. In the foreword to his big collection of essays In Defense of Reason (2011), Winters categorizes literary theories in didactic, pleasure-seeking, and romantic theories, to which he enhances a fourth heading, the moralistic, with which he feel sorry for. According to him, didactic theories are also engrossed with a moralistic element of literature; Winter declares this kind of theories is fascinated in literature as providing obvious moral teaching, and Winters have faith in this mission may be better accomplished by religion or morals, as a substitute of literature. Oddly, not only those theories which see pleasure as the objective of literature are categorized as hedonistic, but also those which see the poem as a reality in it, separate from any outer reality; Winters categorizes T. S. Eliot as a 
doctrinaire in this convention, and Winters, separates himself a great deal from what is usually known as New Criticism. Romantic theories are individualistic-subjectivist theories. In conclusion Winters explains the theory he protects as absolutist. The work of literature, for Winters, "approximates a real fear and communication of a particular kind of objective truth" (Winter; 1999. p. 11). In the end, Winters also acknowledges the faith contained in his absolutist theory, although he observes that "my critical and moral notions are derived from the observation of literature and of life, and that my theism is derived from my critical and moral notions" (Winter; 1999. p. 14). The poetic meaning, feeling, or notion the poet wants to carry, are deeply influenced or even relatively determined by the proper resources; poetry is not the version of a spiritual content in somewhat variable proper pacts, these formal possessions show a vigorous role in the production of the poetic feeling which is the objective of the poem. Winters says that "the poet who suffers from such difficulties in its place of profiting by them is only in a rather rough sense a poet at all" (Winter; 2011. p. 28). In its mixture of words, rhymes, juxtapositions, connotations, cadences, the poem composes itself as "an almost fluid complex," whose rhythms are "faster and more highly organized than are those of prose" (Winter; 2011. p. 32). The involvement carried in verse is deeper and dense, thus more respected, than in prose. For Winters, the defining quality of lyrical poetry is "the quality of transferable or widespread experience," (Winter; 2011. p. 19) the fact that the poem is overall and exacting at the same time. The poem incomes from an internal understanding of the poet, even though the poem itself is relatively a different experience. We could say that Winters's beliefs about the poem is: the poem could be seen as an inspired thing causing from a spiritual and linguistic presentation by the poet, involving of words, rhythms, meter etc. Winters repeats us that "the spiritual control in a poem, then, is simply a manifestation of the spiritual control within the poet," the poem would be a "technique of contemplation, which does not ignore the need of philosophy or religion, but completes and improves them" (Winter; 2011. pp.21-22). The mystical mechanism within the poet could be, consequently, felt in the poem. Winters demonstrates it with the "limpness" one feels in the versification of T. S. Eliot, correlative of the transcendent limpness notifying it; Winters then arrives at a kind of consequence:

\begin{abstract}
This quality, form, is not something outside the poet, something "aesthetic" and superimposed upon his moral content; it is essentially a part, in fact it may be the decisive part, of the moral content, even though the poet may be arriving at the final perfection of the condition he is communicating while he communicates it and in a large measure as a result of the act and technique of communication (Winter; 2011. P. 22).
\end{abstract}

Done the scolding of nonphysical mechanism, verbalization and proper rightness, from poem to poem, the poet improves him or herself. This improving is reformist from poet to poet in literary history, as well as from poem to poem in the history and artistic growth of a particular poet. The reader joins in this nonphysical movement, and this is the honest sense of poetry. The superiority of the spiritual experience of the poet will reveal, in form and content and this will reflect on the reader, who takes a part of the poet's experience in his or her own moral development. So, the importance of the poem will be thoroughly connected to the clarity of language and manifestation as well as the quality and intricacy of the experience being expanded. This is way that poetry achieves its character in human existence. This policy relatively explains the statement of Allen Tate according to which "the poet is responsible for his own conscience," since the poem will be a full replication of his integrity and, consequently, will influence the conscience of those who read it.

\title{
3. Conclusion
}

The principles, morals and purpose of poetry lie in its accuracy and honesty to the state of mind it is work with, not in its leitmotifs, and standards and function of poetry, for Winters, Allen Tate and T. S. Eliot lie first in its linguistic explanation, meanwhile the poet is in charge for the superiority of his people's language. Here Richards's theory brings an important argument when the critic says that "the arts are our storehouse of recorded values" stand up from the artist's experiences and ingeniously established in the artistic work. Therefore, even if the worth of language should be the poet's main concern, the experiences being articulated are also very vital, since a wide range of experiences and feelings will somehow "press" new linguistic solutions and, therefore, upturn the linguistic field. But we must also summon up the importance put by Winters on the formal elements, cadence, meter, rhyme and assonance, amongst others; According to him, these elements are the extreme position in the composition of the poem, their role beyond those of simple arbitrary conventions. Formal rules in poetry are important for a further "scrutinizing" of the language, preventing pure subjectivity and forcing the poet into probing new answers. Winters, Allen Tate and T. S. Eliot have religious beliefs, while Richards supports sophisticated thoughts, and in Pound this ontology is not comparatively perfect. However different their ontological trainings, they seem to reach at somehow equivalent axiological ends. Consequently, we could say that a poem's meaning will be the result of the poet's linguistic ability under the loads of the experience he or she wants to develop sifted through the formal pressures of poetic convention. Such an attempt provides an art object in which language is extremely focused in meaning and form, ensuring a unique experience for both poet and reader. Pound is still more pragmatic in his gratitude of the role of the poetry in its society. In his views, poetry obtains the position of a science which should reach the greatest possible accuracy and neutrality. The standards and morality of poetry lies in its accuracy and honesty to the state of mind it is trade with, not in its themes. Eliot bonds with Pound a particular apprehension with the collective role of poetry and, less pragmatic than Pound, he highlights the importance of the poet's closeness with the history of his language "in use," i.e. the language as it was best used during its history, mainly by the poets of the past, through which he will come to produce works meaningful for those of more 
refined sensibility in his culture, but also capable of saying something to other speakers. Eliot's theory, then, highlights the connection of tradition and the social role of poetry, surrounding the existence and role of poetry through the history of its language and nation as well as throughout all of its speakers, with the process of the poet purifying his own awareness to become part of his tradition. We could say that among the theories debated here, Eliot's is perhaps the most organic, since it sees a natural correlation and intertwining of the development of the poet as an distinct artist with that of his people, and of his tradition. As we see, the conclusions the theories reach point to the idea that art's standards is dependent on its correctness and honesty concerning the experience being condensed. The experiences of a people are what ground its moral and moral development, but they cannot be sufficiently drawn upon if they are not sufficiently registered, not only in their content but also in their emotional and sensorial tones, and art in its various forms is the only possible way of cataloguing them. Art who is not truthful and authentic in process these experiences is disparaging and, consequently, establishes the only actually immoral art. The duty of the poet is no smaller than that of the physician, and he is in charge for the sterility in language as the physician is responsible for sterility in language.

\section{References}

Eliot, T. S. (1975a) Religion and Literature. In: Eliot, T. S. Selected Prose of T. S. Eliot. Edited by Frank Kermode. Farrar, Straus \& Giroux, New York.

Eliot, T. S. (1975b) The Social Function of Poetry, In: Eliot, T. S. On Poetry and Poets. Farrar, Straus \& Giroux, New York.

Eliot, T. S. (1975c) Tradition and the Individual Talent, In: Eliot, T. S. Selected Prose of T. S. Eliot. Edited by Frank Kermode. Farrar, Straus \& Giroux, New York.

Pound, E. (2008) How to Read. In: Davis, G. (org.), praising it New: The Best of the New Criticism. Swallow Press, Ohio.

Pound, E. (1968) The Serious Artist, In: Pound, E., Literary Essays of Ezra Pound. Edited by T. S. Eliot. New Directions, New York.

Ransom, J. C. (1941) The New Criticism. Greenwood Press, Publishers, Connecticut, 1979 (reproduced from the first edition, New Directions.

Richards, I. A. (2001) Principles of Literary Criticism. Rutledge, London and New York.

Tate, Allen. (1999) To Whom is the Poet Responsible? In: Essays of Four Decades. ISI

Books, Wilmington.

Winters, Y. (2011) A Foreword. In Defense of Reason. Rutledge and Kegan Paul Ltd, London.

Winters, Y. (2011) The Morality of Poetry, In: In Defense of Reason. Rutledge and Kegan Paul Ltd, London. 